\title{
A Novel Wistar Rat Model of Obesity-Related Nonalcoholic Fatty Liver Disease Induced by Sucrose-Rich Diet
}

\author{
Maria Luíza R. P. Lima, ${ }^{1}$ Laura H. R. Leite, ${ }^{2}$ \\ Carolina R. Gioda, ${ }^{3}$ Fabíola O. P. Leme, ${ }^{4}$ Claudia A. Couto, ${ }^{1}$ Cândido C. Coimbra, ${ }^{5}$ \\ Virginia H. R. Leite, ${ }^{6}$ and Teresa Cristina A. Ferrari ${ }^{1}$ \\ ${ }^{1}$ Departamento de Clínica Médica, Faculdade de Medicina, Universidade Federal de Minas Gerais, \\ Avenida Professor Alfredo Balena 190, 30130-100 Belo Horizonte, MG, Brazil \\ ${ }^{2}$ Departamento de Fisiologia, Instituto de Ciências Biológicas, Universidade Federal de Juiz de Fora, \\ 36036-900 Juiz de Fora, MG, Brazil \\ ${ }^{3}$ Instituto de Ciências Biológicas, Universidade Federal do Rio Grande, Carreiros, 96203-900 Rio Grande, RS, Brazil \\ ${ }^{4}$ Departamento de Veterinária Clínica e Cirúrgica, Escola de Veterinária, Universidade Federal de Minas Gerais, \\ 31270-901 Belo Horizonte, MG, Brazil \\ ${ }^{5}$ Departamento de Fisiologia e Biofísica, Instituto de Ciências Biológicas, Universidade Federal de Minas Gerais, \\ 31270-901 Belo Horizonte, MG, Brazil \\ ${ }^{6}$ Departamento de Anatomia Patológica e Medicina Legal, Faculdade de Medicina, Universidade Federal de Minas Gerais, \\ 30130-100 Belo Horizonte, MG, Brazil
}

Correspondence should be addressed to Teresa Cristina A. Ferrari; tferrari@medicina.ufmg.br

Received 10 July 2015; Accepted 11 August 2015

Academic Editor: Kimber Stanhope

Copyright ( 2016 Maria Luíza R. P. Lima et al. This is an open access article distributed under the Creative Commons Attribution License, which permits unrestricted use, distribution, and reproduction in any medium, provided the original work is properly cited.

The pathogenesis of nonalcoholic fatty liver disease (NAFLD) is not fully understood, and experimental models are an alternative to study this issue. We investigated the effects of a simple carbohydrate-rich diet on the development of obesity-related NAFLD and the impact of physical training on the metabolic abnormalities associated with this disorder. Sixty Wistar rats were randomly separated into experimental and control groups, which were fed with sucrose-enriched (18\% simple carbohydrates) and standard diet, respectively. At the end of each experimental period (5,10,20, and 30 weeks), 6 animals from each group were sacrificed for blood tests and liver histology and immunohistochemistry. From weeks 25 to 30, 6 animals from each group underwent physical training. The experimental group animals developed obesity and NAFLD, characterized histopathologically by steatosis and hepatocellular ballooning, clinically by increased thoracic circumference and body mass index associated with hyperleptinemia, and metabolically by hyperglycemia, hyperinsulinemia, hypertriglyceridemia, increased levels of very low-density lipoprotein(VLDL-) cholesterol, depletion of the antioxidants liver enzymes superoxide dismutase and catalase, and increased hepatic levels of malondialdehyde, an oxidative stress marker. Rats that underwent physical training showed increased high-density lipoprotein(HDL-) cholesterol levels. In conclusion, a sucrose-rich diet induced obesity, insulin resistance, oxidative stress, and NAFLD in rats.

\section{Introduction}

Over the last decades, obesity has become a global epidemic and an important public health problem in many countries [1]. This condition is largely due to excessive consumption of saturated fats and simple sugars $[2,3]$, which, associated with sedentarism, represent the modern lifestyle [4]. Obesity is recognized as a risk factor for many disorders including type-2 diabetes and nonalcoholic fatty liver disease (NAFLD). NAFLD encompasses a spectrum of increasingly severe clinicopathological conditions ranging from fatty liver to steatohepatitis (NASH) with or without hepatic fibrosis/cirrhosis. 
Recent evidence suggests that NAFLD is also associated with cardiovascular and chronic kidney disease [5] and increased risk of hepatocellular carcinoma [5-8].

It has been considered that insulin resistance and hyperinsulinemia play a key role in the pathogenesis of NALFD (first causative step). Excessive deposition of fat in adipocytes and muscles determines insulin resistance with subsequent accumulation of fat in the liver [9], which, in turn, increases the rate of mitochondrial beta-oxidation of fatty acids and ketogenesis that can promote lipid peroxidation and accumulation of reactive oxygen species (ROS) in the hepatocytes $[10,11]$. These compounds generate a variety of cellular stimulations with subsequent inflammatory response, which has been recognized as the causal factor of NASH/fibrosis (second causative step) $[12,13]$.

In spite of growing knowledge, several aspects of NAFLD pathogenesis are still unknown. Considering the difficulty in developing human studies to evaluate the influence of nutrition in the development of NAFLD and associated metabolic abnormalities, experimental models constitute a reliable alternative way. Different animal models of NAFLD/NASH have been developed, but few of them replicate the entire human phenotype $[12,14]$. These models may be classified into three basic categories: those caused by either spontaneous or induced genetic mutation; those produced by either dietary or pharmacological manipulation; and those involving genetic mutation and dietary or chemical challenges. The dietary manipulations used in these last two types of models usually do not resemble human dietary pattern. In the present study, we developed a model of obesity and obesityrelated NAFLD in nongenetically modified Wistar rats using a simple carbohydrate-rich diet, which resembles the current dietary pattern of humans, and followed the sequence of the pathophysiologic events and their clinical and metabolic consequences. In this context, it should be noted that, in the vast majority of studies on NAFLD in which animal models were employed, the description of the sequence of the pathophysiologic events and their consequences have not been addressed, as their key goal is usually the evaluation of a specific aspect such as a therapeutic intervention. Furthermore, we evaluated the impact of physical training on the metabolic abnormalities associated with this disorder.

\section{Material and Methods}

2.1. Animals and Experimental Design. Sixty male Wistar rats, approximately 28 days old (after weaning), were housed individually and had free access to water and rat diet. The animals were randomly separated into the following groups: experimental group (EG), fed with highly palatable diet (see below) during 5 (EG5, 6 rats), 10 (EG10, 6 rats), 20 (EG20, 6 rats), and 30 (EG30, 12 rats) weeks, and control group (CG), fed with standard rat chow during 5 (CG5, 6 rats), 10 (CG10, 6 rats), 20 (CG20, 6 rats), and 30 (CG30, 12 rats) weeks. From week 25 to week 30, 12 animals belonging to the EG30 (6 rats) and CG30 (6 rats) were submitted to physical training (see below).

At the end of each experimental period, after fasting for 10 hours, the animals were sacrificed. Blood samples were taken by cardiac puncture and stored at $-20^{\circ} \mathrm{C}$. The livers were immediately removed and fragments of about $1 \mathrm{~mm}$ thickness were fixed in $4 \%$ formaldehyde, dehydrated, immersed in xylene, and then embedded in paraffin for histology. Fresh tissue samples were collected to evaluate antioxidant enzymes activity.

All experiments were approved by the Ethics Committee of the Universidade Federal de Minas Gerais for the Care and Use of Laboratory Animals (CETEA 53/2007) and were carried out in accordance with the regulations described in the Committee's Guiding Principles Manual. A rat belonging to the CG20 died and was excluded from all analyses.

2.2. Diet. The standard rat chow (Nuvilab-CR1 NuvitalColombo, Brazil) had the following nutrient composition: protein, $22 \%$; fat, $4 \%$; carbohydrate, $42 \%$; minerals, $10 \%$; phosphorus, $0.8 \%$; vitamins, $1 \%$; fiber, $8 \%$; water, $12.5 \%$. The chemical analysis revealed that $100 \mathrm{~g}$ of this diet contained $309 \mathrm{kcal}, 24.8 \mathrm{~g}$ of protein, $3.4 \mathrm{~g}$ of fat, $44.8 \mathrm{~g}$ of carbohydrates, $8.2 \mathrm{~g}$ of fixed mineral residue, and $18.8 \mathrm{~g}$ of dietary fiber. The diet known as effective in inducing obesity in rats and described as highly palatable was composed of what follows: $33 \%$ of standard rat chow compacted to powder, $33 \%$ of condensed milk (Moça, Nestlé, Brazil), $7 \%$ of sucrose (refined sugar, União, Brazil), and $27 \%$ of water [15]. The condensed milk was nutritionally composed of carbohydrate, $56.7 \%$; fat, $8.3 \%$; protein, $6.7 \%$; water, $28.3 \%$. According to the chemical analysis, $100 \mathrm{~g}$ of dried highly palatable diet contained $339 \mathrm{kcal}, 16.1 \mathrm{~g}$ of protein, $3.4 \mathrm{~g}$ of fat, $61 \mathrm{~g}$ of carbohydrates (18\% of simple carbohydrates), $5.1 \mathrm{~g}$ of fixed mineral residue, and $14.4 \mathrm{~g}$ of dietary fiber.

The diet was prepared daily, weighed, fractionated in portions, and stored in the feeder for 8-10 hours. The remaining food in the feeder was weighed to calculate the final amount of ingested food. The water content of the drinking bottles was renewed daily.

\subsection{Anthropometric Parameters and Physical Training. On a} weekly basis, the body weight, thoracic circumference (TC) (measured between the foreleg and hind leg), and nasoanal length were measured. Body mass index (BMI), that is, the ratio between body weight ( $\mathrm{g}$ ) and the square of body length $\left(\mathrm{cm}^{2}\right)$, was calculated [16].

All animals were acclimatized to exercise on the motordriven treadmill (Gaustec, Brazil) by running at a speed of $10 \mathrm{~m} \cdot \mathrm{min}^{-1}$ at $5 \%$ inclination for 5 minutes/day, during 5 consecutive days. After exercise familiarization, trained rats were submitted to the physical training protocol, which consisted of running sessions with gradual increase in intensity across 5 weeks, 5 days/week. The speed and duration of the exercise bouts were increased until the rats were able to run at $25 \mathrm{~m} \cdot \mathrm{min}^{-1}, 5 \%$ inclination, during 60 minutes/day. The achievement of this exercise intensity ensures that a significant endurance training effect is produced [17]. In order to ensure that all animals were subjected to the same handling stress, untrained group was submitted to running exercise on the same days of physical training, at the same speed, but for 2 minutes only [17]. 
2.4. Analytical Procedures of Blood Parameters. Measurement of glucose, total cholesterol, very low-density lipoprotein(VLDL-) cholesterol, low-density lipoprotein (LDL-) cholesterol, high-density lipoprotein- (HDL-) cholesterol, and triglycerides was performed as recommended by the manufacturer (Bioclin, Quimbasa, Basic Chemistry Ltda, Brazil) using an autoanalyzer (StatPlus 2300, Yellow Spring Inst, USA).

Serum concentrations of leptin and insulin were determined by radioimmunoassay (Rat Leptin Ria Kit, Rat Insulin Ria Kit, LINCO Research, USA) using a gamma-ray counter (Mor-ABBOT, USA). The minimum detection value was $0.5 \mathrm{ng} / \mathrm{mL}$.

2.5. Evaluation of Antioxidant Enzyme Activity. The determination of superoxide dismutase (SOD) activity was adapted from Dieterich et al. [18]. Briefly, fresh liver samples were homogenized in $50 \mathrm{mM}$ sodium phosphate buffer $(1 \mathrm{~mL}, \mathrm{pH}$ $7.8,37^{\circ} \mathrm{C}$ ) and $1 \mathrm{mM}$ of diethylenetriamine pentaacetic acid (DTPA), immediately after their removal. The reaction was initiated by addition of pyrogallol acid $\left(0.2 \mathrm{mM} / \mathrm{L}, 37^{\circ} \mathrm{C}\right.$ for 3 minutes) and the absorbance measured at $420 \mathrm{~nm}$. SOD activity was calculated as $\mathrm{U} / \mathrm{mg}$ protein, where $1 \mathrm{U}$ of the enzyme was defined as the amount required to inhibit the oxidation of pyrogallol by $50 \%$.

Catalase (CAT) activity was measured in the supernatant of liver homogenate as described by Nelson and Kiesow [19]. Briefly, $0.04 \mathrm{~mL}$ of $\mathrm{H}_{2} \mathrm{O}_{2}, 0.06 \mathrm{~mL}$ of liver homogenate, and $1.9 \mathrm{~mL}$ of potassium phosphate buffer $(50 \mathrm{mM}, \mathrm{pH} 7.0)$ were mixed to give a final concentration of $6 \mathrm{mM}$ of $\mathrm{H}_{2} \mathrm{O}_{2}$. It took 1 minute for the reaction to occur at room temperature. The decomposition of $\mathrm{H}_{2} \mathrm{O}_{2}$ by CAT was evaluated by the change in absorbance at $240 \mathrm{~nm}$. The experiments were performed in duplicate. CAT activity was expressed as mmol of $\mathrm{H}_{2} \mathrm{O}_{2}$ decomposed per minute per milligram of protein. This procedure was adopted to avoid the possibility of interference in the activity of glutathione peroxidase, once the necessary cofactors were not present in the reaction medium.

2.6. Histological and Immunohistochemistry Evaluations. Histological sections were prepared from the material embedded in paraffin and stained with hematoxylin-eosin. The histological analysis was performed simultaneously by two examiners. The criteria established by Brunt et al. were used to describe the histological lesions. According to these criteria, macrovesicular steatosis is quantified based on the percentage of involved hepatocytes $(0=$ absent; $1<33 \%$; $2=33-66 \% ; 3>66 \%$ ), and its zonal distribution and the presence of microvesicular steatosis are noted; hepatocellular ballooning is evaluated for zonal location, and the estimate of its severity (mild, marked) is based on the numbers of hepatocytes showing this abnormality [20].

Hepatic expression of malondialdehyde (MDA), leptin, and the leptin receptor Ob-R was evaluated by immunohistochemistry in the animals sacrificed at weeks 20 and 30. From paraffin embedded tissues, sections on salinized slides $(4 \mathrm{~mm})$ were collected, deparaffinized, and hydrated. For immunohistochemistry, antigen reaction with ethylenediaminetetraacetic acid (EDTA) at $\mathrm{pH} 8.0$, no steamer for
TABLE 1: Comparison of anthropometric parameters between experimental and control groups.

\begin{tabular}{lccc}
\hline \multirow{2}{*}{ Time (weeks) } & \multicolumn{2}{c}{ Groups } & P value \\
& \multicolumn{4}{c}{$\Delta$ BMI $\left(\mathrm{kg} / \mathrm{cm}^{2}\right)^{\dagger}$} \\
5 & $0.25( \pm 0.09)$ & $0.36( \pm 0.07)$ & 0.032 \\
10 & $0.26( \pm 0.14)$ & $0.27( \pm 0.08)$ & 0.082 \\
20 & $0.48( \pm 0.09)$ & $0.40( \pm 0.10)$ & 0.193 \\
30 & $0.50( \pm 0.15)$ & $0.34( \pm 0.06)$ & 0.003 \\
\hline \multicolumn{4}{c}{$\Delta$ Thoracic circumference $(\mathrm{cm})^{\dagger}$} \\
5 & $6.67( \pm 0.45)$ & $6.67( \pm 0.80)$ & 1.000 \\
10 & $10.48( \pm 1.86)$ & $8.32( \pm 2.04)$ & 0.083 \\
20 & $12.00( \pm 1.27)$ & $9.02( \pm 1.03)$ & 0.002 \\
30 & $13.82( \pm 2.84)$ & $9.85( \pm 1.30)$ & 0.031 \\
\hline
\end{tabular}

${ }^{*} t$-test; ${ }^{\dagger}$ mean \pm standard deviation.

30 minutes at $98^{\circ} \mathrm{C}$, was conducted, followed by Tris $\mathrm{HCl}$ $\mathrm{pH} 7.6$ washing. The whole procedure was performed using Polymer Detection System kit (Novolink Polymer Detection System, Novocastra, USA). The primary antibodies used were anti-MDA monoclonal antibody (1F83) (Cosmo Bio Co., Ltd., Japan) diluted in $0.5 \mathrm{~mL}$; anti-Ob (A-20) sc-84; and anti-Ob-R (H-300) sc-8325 (Santa Cruz Biotechnology Inc., USA) at a dilution of $1: 250$ and $1: 100$, respectively.

2.7. Statistical Analysis. Data are presented as frequencies and percentages, mean \pm standard deviation (SD), and median and interquartile range (IQR). For each quantitative response's variables, we developed linear regression models in which all variables with $P$ value $\leq 0.25$ at univariate analysis would be included initially. However, due to the high level of correlation between the explanatory covariates, we opted to adjust the final model with the following covariates: group, physical training, variation in $\mathrm{BMI}(\triangle \mathrm{BMI})$, and variation in the amount of ingested calories ( $\Delta \mathrm{Kcal})$. The adequacy of the models was assessed by analysis of the residues. For the categorical variables, logistic regression models were developed, with inclusion of the variables that showed on the univariate analysis a $P$ value $\leq 0.25$, and also clinical significance. The model fit was assessed by the HosmerLemeshow test. Statistical analysis was performed using the $\mathrm{R}$ public domain software. Significance level was set at $P$ value $<0.05$.

\section{Results}

3.1. Descriptive Analysis of the Variables and Comparison between EG and CG. The results of the anthropometric parameters, lipid and glucose profile, hormones levels, and antioxidant enzymes activity, as well the results of their comparative analyses between EG and CG along the time of follow-up, are described in Tables 1, 2, and 3. Insulin (Figure 1(a)) and leptin (Figure 1(b)) serum levels varied inversely over time in the EG.

Liver histology was normal (Figure 2(a)) in the CG in all times of the experiment. Steatosis and hepatocellular 
TABLE 2: Comparison of biochemical parameters between experimental and control groups.

\begin{tabular}{|c|c|c|c|}
\hline \multirow{2}{*}{ Time (weeks) } & \multicolumn{2}{|c|}{ Groups } & \multirow{2}{*}{$P$ value ${ }^{*}$} \\
\hline & Experimental & Control & \\
\hline \multicolumn{4}{|c|}{ Glucose $(\mathrm{mg} / \mathrm{dL})^{\dagger}$} \\
\hline 5 & $272.3( \pm 92.5)$ & $176.2( \pm 27.1)$ & 0.035 \\
\hline 10 & $434.5( \pm 214.5)$ & $307.2( \pm 121.9)$ & 0.235 \\
\hline 20 & $324.2( \pm 53.4)$ & $279.4( \pm 133.8)$ & 0.468 \\
\hline 30 & $463.1( \pm 101.7)$ & $299.8( \pm 78.6)$ & $<0.001$ \\
\hline \multicolumn{4}{|c|}{ Total cholesterol $(\mathrm{mg} / \mathrm{dL})^{\dagger}$} \\
\hline 5 & $83.5( \pm 18.0)$ & $72.8( \pm 20.6)$ & 0.363 \\
\hline 10 & $64.5( \pm 13.1)$ & $73.2( \pm 7.9)$ & 0.194 \\
\hline 20 & $108.0( \pm 33.3)$ & $85.8( \pm 21.0)$ & 0.231 \\
\hline 30 & $104.3( \pm 33.6)$ & $80.6( \pm 15.0)$ & 0.099 \\
\hline \multicolumn{4}{|c|}{ HDL-cholesterol (mg/dL) ${ }^{\ddagger}$} \\
\hline 5 & $49.1(22.9-65.3)$ & $39.2(22.9-64.1)$ & 0.779 \\
\hline 10 & $34.8(23.0-52.8)$ & $42.3(37.7-49.7)$ & 0.689 \\
\hline 20 & $49.6(44.0-69.5)$ & $57.9(56.8-63.7)$ & 0.315 \\
\hline 30 & $65.8(51.8-75.3)$ & $64.0(51.1-79.4)$ & 1.000 \\
\hline \multicolumn{4}{|c|}{ VLDL-cholesterol $(\mathrm{mg} / \mathrm{dL})^{\ddagger}$} \\
\hline 5 & $20.5(14.3-25.9)$ & $13.7(10.9-18.9)$ & 0.149 \\
\hline 10 & $17.4(14.1-35.7)$ & $17.9(13.5-19.2)$ & 0.522 \\
\hline 20 & $17.1(11.8-24.3)$ & $11.0(9.0-14.1)$ & 0.083 \\
\hline 30 & $26.3(22.1-49.8)$ & $11.0(9.1-17.0)$ & $<0.001$ \\
\hline \multicolumn{4}{|c|}{ LDL-cholesterol $(\mathrm{mg} / \mathrm{dL})^{\dagger}$} \\
\hline 5 & $24.8( \pm 21.6)$ & $24.8( \pm 12.2)$ & 1.000 \\
\hline 10 & $23.7( \pm 26.5)$ & $12.7( \pm 6.0)$ & 0.343 \\
\hline 20 & $34.6( \pm 22.6)$ & $19.5( \pm 16.6)$ & 0.246 \\
\hline 30 & $38.4( \pm 18.1)$ & $15.0( \pm 10.7)$ & 0.341 \\
\hline \multicolumn{4}{|c|}{ Triglycerides $(\mathrm{mg} / \mathrm{dL})^{\ddagger}$} \\
\hline 5 & $102.5(71.5-129.5)$ & $68.5(54.5-94.3)$ & 0.150 \\
\hline 10 & $87.0(70.5-178.3)$ & $89.5(67.3-95.8)$ & 0.522 \\
\hline 20 & $85.5(58.8-121.5)$ & $55.0(45.0-70.5)$ & 0.083 \\
\hline 30 & $131.5(110.5-248.8)$ & $55.0(45.3-85.0)$ & $<0.001$ \\
\hline
\end{tabular}

${ }^{*} t$-test for normally distributed and Mann-Whitney test for nonnormally distributed variables; ${ }^{\dagger}$ mean \pm standard deviation; ${ }^{\ddagger}$ median (interquartile range).

ballooning (Figures 2(b) and 2(c)) were observed only in the EG, from week 10. Steatosis was macro- and microvacuolar, located predominantly in zone 3 of the liver acinus. The intensity of the macrovacuolar steatosis varied from mild (involvement of less than 33\% of the hepatocytes) to severe (involvement of more than $66 \%$ of the hepatocytes) regardless of the time of the experiment. Ballooning was localized in zones 2 and 3 of the acinus, ranging from mild to marked and mismatched with the time of experiment. Neither inflammatory foci nor fibrosis was observed.

The reaction for identifying MDA (Figure 2(d)) was positive and intense, of cytoplasmic localization in zone 3 of the hepatic acinus, around the central vein, in EG20 and EG30. No MDA was detected in CG rats. Leptin (Figure 2(e)) was identified in the cytoplasm especially in zone 3 of the acinus, in EG20 and EG30. In CG rats, the reaction was
TABLE 3: Comparison of hormonal levels and enzyme activity between experimental and control groups.

\begin{tabular}{|c|c|c|c|}
\hline \multirow{2}{*}{ Time (weeks) } & \multicolumn{2}{|c|}{ Groups } & \multirow{2}{*}{$P$ value* } \\
\hline & Experimental & Control & \\
\hline \multicolumn{4}{|c|}{ Insulin $(\mu \mathrm{L})^{\ddagger}$} \\
\hline 5 & $7.6(3.8-11.1)$ & $1.6(1.5-2.1)$ & 0.005 \\
\hline 10 & $4.7(3.4-8.2)$ & $1.7(1.6-3.1)$ & 0.013 \\
\hline 20 & $0.9(0.6-1.1)$ & $0.3(0.3-0.4)$ & 0.008 \\
\hline 30 & $0.4(0.3-0.8)$ & $0.2(0.2-0.4)$ & 0.043 \\
\hline \multicolumn{4}{|c|}{ Leptin $(\mu \mathrm{L})^{\ddagger}$} \\
\hline 5 & $14.3(11.7-18.9)$ & $6.6(5.8-7.6)$ & 0.001 \\
\hline 10 & $13.7(9.6-20.9)$ & $4.4(3.6-4.8)$ & 0.005 \\
\hline 20 & $18.2(10.3-25.9)$ & $5.1(3.3-8.1)$ & 0.021 \\
\hline 30 & $24.7(13.1-37.0)$ & $2.6(1.8-5.7)$ & $<0.001$ \\
\hline \multicolumn{4}{|c|}{ Superoxide dismutase (U/mg protein $)^{\dagger}$} \\
\hline 5 & $1.5( \pm 0.1)$ & $1.6( \pm 0.03)$ & 0.090 \\
\hline 10 & $1.6( \pm 0.02)$ & $1.6( \pm 0.1)$ & 1.000 \\
\hline 20 & $1.6( \pm 0.1)$ & $1.5( \pm 0.1)$ & 0.288 \\
\hline 30 & $0.9( \pm 0.3)$ & $1.4( \pm 0.1)$ & $<0.001$ \\
\hline \multicolumn{4}{|c|}{$\begin{array}{c}\text { Catalase } \\
\left.\text { (mmol of } \mathrm{H}_{2} \mathrm{O}_{2} \text { decomposed/minute/milligram of protein }\right)^{\dagger}\end{array}$} \\
\hline 5 & $15.8( \pm 2.4)$ & $15.9( \pm 2.7)$ & 0.948 \\
\hline 10 & $14.3( \pm 3.1)$ & $15.9( \pm 2.7)$ & 0.411 \\
\hline 20 & $11.8( \pm 1.4)$ & $15.1( \pm 2.9)$ & 0.037 \\
\hline 30 & $14.6( \pm 1.9)$ & $16.7( \pm 3.5)$ & 0.111 \\
\hline
\end{tabular}

${ }^{*} t$-test for normally distributed and Mann-Whitney test for nonnormally distributed variables; ${ }^{\dagger}$ mean \pm standard deviation; ${ }^{\ddagger}$ median (interquartile range).

weakly positive, at the same location. Ob-R was expressed as a weak cytoplasmic reaction predominantly in zone 3 of the acinus, in the rats of both groups, at weeks 20 and 30.

The comparison of the different variables between physical trained and untrained groups showed higher serum levels of HDL-cholesterol in the first group: medians $75 \mathrm{mg} / \mathrm{dL}$ and $52.2 \mathrm{mg} / \mathrm{dL}$, respectively $(P=0.007)$. No other clinical or metabolic variable was significantly different between the groups after the physical training.

3.2. Multivariate Analysis. Table 4 shows the results of the final linear and logistic regressions models. In summary, blood glucose levels were 49\% higher in EG rats than in CG rats, and the rats studied for 10 and 30 weeks had an increase of $49 \%$ and $65 \%$, respectively, in serum glucose compared to those studied for 5 weeks. Total cholesterol was $19.2 \mathrm{mg} / \mathrm{dL}$ higher in the EG in comparison with the CG. Rats undergoing physical training showed an average of $27.1 \mathrm{mg} / \mathrm{dL}$ increase in HDL-cholesterol than those that did not exercise; and each increase of 1 unit in $\Delta \mathrm{kcal}$ intake caused an average reduction of $0.03 \mathrm{mg} / \mathrm{dL}$ in HDL-cholesterol levels. Regarding LDLcholesterol, there was an average increase of $60.2 \mathrm{mg} / \mathrm{dL}$ for each increase of 1 unit in $\triangle B M I$.

Two models were adjusted for the dependent variable insulin. The first, composed by the time (categorical) and 


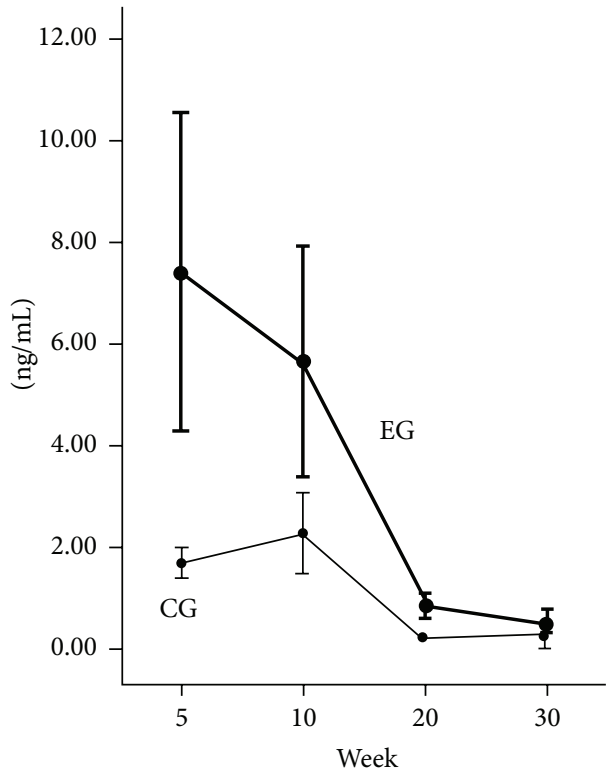

(a)

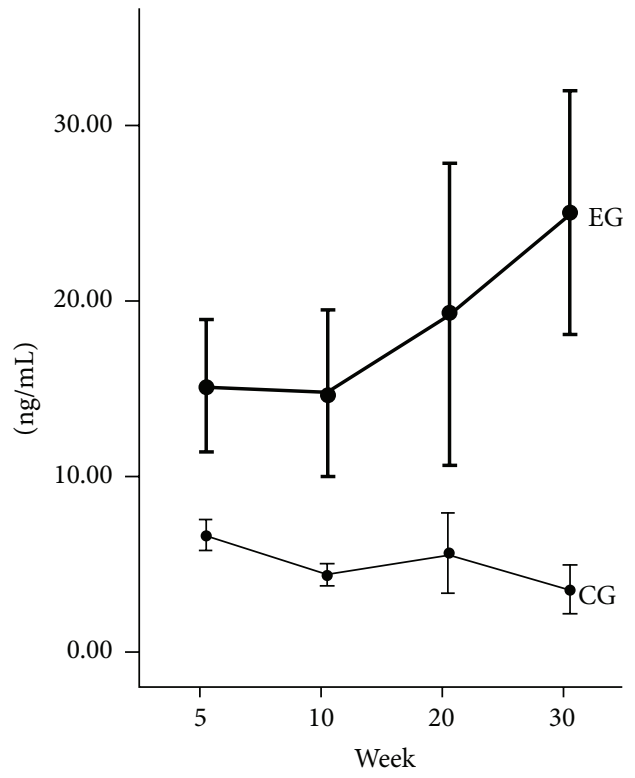

(b)

FIGURE 1: Levels of insulin and leptin over time. Mean and standard deviation of (a) insulin and (b) leptin serum concentrations, over time, in the experimental (EG) and control (CG) groups.

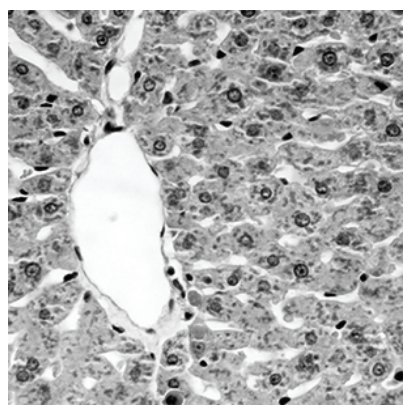

(a)

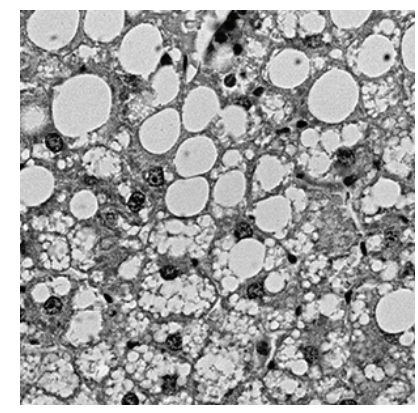

(b)

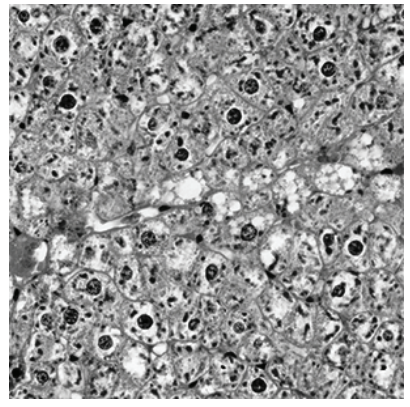

(c)

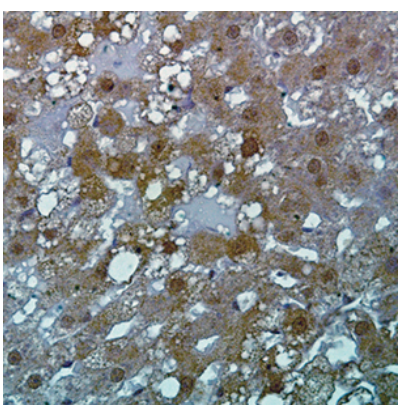

(d)

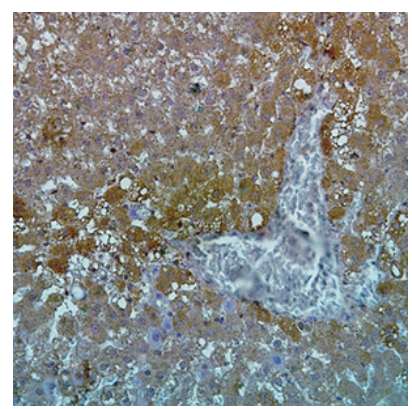

(e)

Figure 2: Liver histology and immunohistochemistry. (a) Rats fed with standard diet (control group) at 30 weeks; normal histology, hematoxylin and eosin stain $\times 10$. (b, c, d, and e) Rats fed a sucrose-rich diet (experimental group) at 30 weeks; (b) macro and micro vacuolar steatosis, and hepatocellular ballooning, hematoxylin and eosin stain, $\times 40$; (c) macro and micro vacuolar steatosis, and hepatocellular ballooning, hematoxylin and eosin stain, $\times 10$. (d) Intense reaction to malondialdehyde $\times 40$; (e) reaction to leptin $\times 20$. 
TABLE 4: Linear and logistic regression models for the response variables.

\begin{tabular}{|c|c|c|c|}
\hline Variable/model & $\begin{array}{l}\text { Coefficient } \\
(95 \% \text { CI })\end{array}$ & $\begin{array}{c}\text { Coefficient } \\
\text { exponential ( } 95 \% \\
\text { CI) }\end{array}$ & $P$ value \\
\hline \multicolumn{4}{|c|}{ Glucose } \\
\hline Constant & \multirow{3}{*}{5.2} & & $<0.001$ \\
\hline \multicolumn{3}{|l|}{ Time (weeks) } & \\
\hline \multicolumn{3}{|l|}{5} & \\
\hline 10 & 0.4 & $1.49(1.1 ; 2.0)$ & 0.005 \\
\hline 20 & 0.3 & $1.35(1.0 ; 1.8)$ & 0.090 \\
\hline 30 & 0.5 & $1.65(1.3 ; 2.1)$ & $<0.001$ \\
\hline \multicolumn{4}{|l|}{ Group } \\
\hline $\mathrm{EG}$ & \multirow[t]{2}{*}{0.4} & \multirow[t]{2}{*}{$1.49(1.3 ; 1.8)$} & \multirow[t]{2}{*}{$<0.001$} \\
\hline CG & & & \\
\hline \multicolumn{4}{|c|}{ Total cholesterol } \\
\hline Constant & \multirow{2}{*}{\multicolumn{2}{|c|}{$177.7(139.3 ; 216.1)$}} & $<0.001$ \\
\hline \multicolumn{2}{|l|}{ Time (weeks) } & & \\
\hline \multicolumn{4}{|l|}{5} \\
\hline 10 & \multicolumn{2}{|l|}{$-25.2(-46.8 ; 3.6)$} & 0.026 \\
\hline 20 & \multicolumn{2}{|l|}{$-50.9(-107.7 ; 5.9)$} & 0.085 \\
\hline 30 & \multicolumn{2}{|l|}{$-40.2(-84.8 ; 4.4)$} & 0.083 \\
\hline \multicolumn{4}{|l|}{ Group } \\
\hline EG & \multicolumn{2}{|l|}{$19.2(4.4 ; 31.2)$} & 0.003 \\
\hline \multicolumn{4}{|l|}{ CG } \\
\hline$\Delta$ Kcal & \multicolumn{2}{|l|}{$-0.1(-0.2 ;-0.03)$} & 0.014 \\
\hline \multicolumn{4}{|c|}{ HDL-cholesterol } \\
\hline Constant & \multicolumn{2}{|c|}{$53.1(46.7 ; 59.5)$} & $<0.001$ \\
\hline \multicolumn{4}{|l|}{ Exercise } \\
\hline Yes & $26.1(12.9 ; 39.4)$ & & $<0.001$ \\
\hline No & & & \\
\hline$\Delta \mathrm{Kcal}$ & $\begin{array}{c}-0.03(-0.05 \\
-0.01)\end{array}$ & & 0.011 \\
\hline & LDL-choleste & rol & \\
\hline Constant & $2.8(-16.3 ; 21.9)$ & & 0.774 \\
\hline$\Delta \mathrm{BMI}$ & $60.2(11.9 ; 108.6)$ & & 0.018 \\
\hline & Insulin (first m & odel) & \\
\hline Constant & 0.8 & & $<0.001$ \\
\hline Time (weeks) & & & \\
\hline 5 & & & \\
\hline 10 & -0.005 & $1.00(0.67 ; 1.47)$ & 0.980 \\
\hline 20 & -1.8 & $0.17(0.11 ; 0.24)$ & $<0.001$ \\
\hline 30 & -2.2 & $0.11(0.07 ; 0.16)$ & $<0.001$ \\
\hline Group & & & \\
\hline EG & 0.8 & $2.23(0.18 ; 2.70)$ & $<0.001$ \\
\hline CG & & & \\
\hline & Insulin (second 1 & model) & \\
\hline Constant & 0.7 & & 0.011 \\
\hline Time (quantitative) & -0.07 & $0.93(0.91 ; 0.95)$ & $<0.001$ \\
\hline Group & & & \\
\hline EG & 0.7 & $2.01(1.65 ; 2.45)$ & $<0.001$ \\
\hline CG & & & \\
\hline$\Delta$ Kcal & 0.002 & $1.002(1.001 ; 1.003)$ & 0.004 \\
\hline
\end{tabular}

TABLE 4: Continued.

\begin{tabular}{|c|c|c|c|}
\hline Variable/model & $\begin{array}{l}\text { Coefficient } \\
(95 \% \mathrm{CI})\end{array}$ & $\begin{array}{c}\text { Coefficient } \\
\text { exponential (95\% } \\
\text { CI) }\end{array}$ & $P$ value \\
\hline \multicolumn{4}{|c|}{ Leptin } \\
\hline Constant & 0.8 & & $<0.001$ \\
\hline \multicolumn{4}{|l|}{ Time (weeks) } \\
\hline \multicolumn{4}{|l|}{5} \\
\hline 10 & -0.1 & $0.90(0.61 ; 1.33)$ & 0.450 \\
\hline 20 & -0.4 & $0.67(0.45 ; 0.99)$ & 0.047 \\
\hline 30 & -0.5 & $0.60(0.41 ; 0.90)$ & 0.004 \\
\hline \multicolumn{4}{|l|}{ Group } \\
\hline EG & 1.3 & $3.67(3.01 ; 4.46)$ & $<0.001$ \\
\hline \multicolumn{4}{|l|}{ CG } \\
\hline$\Delta \mathrm{BMI}$ & 2.6 & $13.46(5.1 ; 35.87)$ & $<0.001$ \\
\hline \multicolumn{4}{|c|}{ Superoxide dismutase } \\
\hline Constant & 0.7 & & $<0.001$ \\
\hline \multicolumn{4}{|l|}{ Time (weeks) } \\
\hline \multicolumn{4}{|l|}{5} \\
\hline 10 & -0.03 & $0.97(0.85 ; 1.11)$ & 0.606 \\
\hline 20 & 0.10 & $1.11(0.96 ; 1.27)$ & 0.156 \\
\hline 30 & -0.27 & $0.76(0.68 ; 0.86)$ & $<0.001$ \\
\hline \multicolumn{4}{|l|}{ Group } \\
\hline EG & -0.12 & $0.89(0.82 ; 0.96)$ & 0.006 \\
\hline \multicolumn{4}{|l|}{ CG } \\
\hline$\Delta \mathrm{IMC}$ & -0.77 & $0.46(0.32 ; 0.67)$ & $<0.001$ \\
\hline \multicolumn{4}{|c|}{ Catalase } \\
\hline Constant & $16.6(15.0 ; 18.3)$ & & $<0.001$ \\
\hline \multicolumn{4}{|l|}{ Time (weeks) } \\
\hline \multicolumn{4}{|l|}{5} \\
\hline 10 & $-0.7(-2.9 ; 1.6)$ & & 0.564 \\
\hline 20 & $-2.4(-4.6 ; 0.2)$ & & 0.041 \\
\hline 30 & $-0.1(-2.1 ; 1.8)$ & & 0.902 \\
\hline \multicolumn{4}{|l|}{ Group } \\
\hline EG & $-1.8(-3.2 ; 0.4)$ & & 0.016 \\
\hline \multicolumn{4}{|l|}{ CG } \\
\hline \multicolumn{2}{|l|}{ Model/variable } & $\begin{array}{l}\text { Odds ratio }(95 \% \\
\text { CI })\end{array}$ & $P$ value \\
\hline \multicolumn{4}{|c|}{ Steatosis } \\
\hline$\Delta \mathrm{TC}$ & & $1.50(1.10 ; 1.90)$ & 0.002 \\
\hline \multicolumn{4}{|c|}{ Hepatocellular ballooning } \\
\hline$\Delta \mathrm{TC}$ & & $1.50(1.10 ; 1.90)$ & 0.002 \\
\hline
\end{tabular}

EG, experimental group; CG, control group; Kcal, amount of calorie intake; TC, thoracic circumference.

groups of rats, showed that the EG20 and EG30 had, respectively, lower insulin values of $83 \%$ and $89 \%$ compared to EG5. Furthermore, the animals of EG had an average insulin levels increased by $123 \%$ compared to the CG. The second model, including time (quantitative form), groups of rats, and $\Delta \mathrm{kcal}$ intake, showed that, for each increase of 1 unit in time, the average value of insulin decreased by $7 \%$ and, for each increase of 1 unit in $\Delta \mathrm{kcal}$ intake, the average value of insulin increased by $0.2 \%$. The EG rats had an average insulin level increased by $100 \%$ compared to those of the CG. 
In EG20 and EG30, the leptin values were 33\% and 40\% higher, respectively, compared to the rats followed for 5 weeks. The EG had a mean value of leptin increased by $267 \%$ compared to the CG, and for every increase of 1 unit in $\triangle \mathrm{BMI}$ the average value of leptin increased by $124.6 \%$. The amount of SOD was $24 \%$ lower in the animals followed for 30 weeks in relation to those studied for 5 weeks. In the EG, the mean values of SOD were $11 \%$ lower compared to the CG; and, for each increase of 1 unit in $\triangle \mathrm{BMI}$, the mean SOD values decreased by $54 \%$. The rats studied for 20 weeks presented an average of 2.4 less CAT units than those studied for 5 weeks, and in the EG an average of 1.8 less units of CAT relative to the CG was observed. Concerning the histological findings, it was found that, for each increase of 1 unit in the $\triangle \mathrm{TC}$, the chance of expressing ballooning and steatosis increased by $50 \%$.

\section{Discussion}

This study demonstrates that a diet with high amount of simple carbohydrates, which resembles the current human dietary pattern, was able to induce obesity-related NAFLD, here characterized histologically by hepatic steatosis and hepatocyte ballooning, clinically by increased TC and BMI associated with hyperleptinemia, and metabolically by hyperglycemia, hyperinsulinemia (with subsequent insulin return to baseline levels), hypertriglyceridemia, increased serum levels of VLDL-cholesterol, depletion of antioxidants liver enzymes, and increased levels of MDA, an oxidative stress marker. Furthermore, rats that underwent physical training showed a significant increase in HDL-cholesterol in comparison to those that did not exercise.

High-fat and methionine choline-deficient diets are widely used to produce hepatic steatosis and NASH in experimental animals [12, 14, 21-26]. However, these diets do not reflect the usual dietary pattern of humans regarding their composition. Diets high in both saturated fat and simple carbohydrate have also been commonly used in genetically modified or wild-type animals in experimental models of NAFLD [27-35]. Animal models in which NAFLD was induced by simple carbohydrate-rich diets (usually fructose) are less numerous, and in most of them only hepatic steatosis was observed [28, 36-44]. Although the animal models that combine naturally occurring or induced genetic mutations associated with dietary or chemical challenges resemble the histopathology and pathophysiology of human NAFLD more closely, the dietary challenge is usually performed by high-fat or methionine choline-deficient diets [12, 14, 4547]. Although each of these models is valuable, they fail to address key aspects of the process in humans. For example, few humans have diets that are deficient in methionine and choline. Moreover, rodents exposed to methionine- and choline-deficient diets are not obese; rather, they lose weight and become more insulin-sensitive [48]. On the other hand, the diet used in our investigation was balanced in terms of its content in proteins, lipids, carbohydrates, vitamins, and minerals, in addition to being highly palatable, normocaloric, and fiber containing. Furthermore, it was administered in solid consistency, as pellets, during a relatively long period of time. What has usually been described in the other animal investigations is a rapid induction of obesity due to the administration, in a short period of time, of a high-caloric high-fructose and/or high-fat diet, as liquid in troughs or via a nasogastric tube. In synthesis, we sought to feed the animals with a diet as similar as possible to a normal diet regarding its content as well as its form of administration.

In our study, free access to the sucrose-rich diet and high food consumption caused obesity/abdominal obesity in the EG rats from week 10 . Obesity was associated with increased serum levels of glucose, triglycerides, VLDL-cholesterol, and insulin, which are manifestations of insulin resistance $[9,49]$. The hyperinsulinemia led to increased hepatic synthesis of fatty acids, triglyceride accumulation in the hepatocytes, with subsequent steatosis. Surplus triglyceride was exported as VLDL-lipoprotein. The de novo hepatic lipogenesis, which is aggravated by diets with higher carbohydrate content than fat, plays an important role in glucose homeostasis and development of hypertriglyceridemia and hyperinsulinemia $[50,51]$. For example, when the amount of ingested carbohydrate exceeds the total calorie needs, the rate of de novo hepatic lipogenesis increases by 10 times [52]. Likewise, this rate increases 27 times with the ingestion of a diet with high carbohydrate content compared to low-carbohydrate diets and fasting [53].

A positive correlation between increase in serum levels of leptin and BMI was another finding of this study that corroborates human observations [54]. The hyperleptinemia may be not only a consequence of hyperphagia and obesity, but also a result of the fructose component of the diet, which is in agreement with the study by Vilà et al., which demonstrated induction of hyperleptinemia by fructose [55]. In humans, increased levels of leptin are observed in obese individuals and in patients with NAFLD/NASH. It is suggested that this increase may reflect a state of leptin resistance at central level as well in the muscles and liver [56, 57].

In an attempt to understand the action of leptin in the liver and its possible role in the pathogenesis of NAFLD/NASH, we evaluated the expression of leptin and $\mathrm{Ob}-\mathrm{R}$ in the hepatic parenchyma and found intense leptin reaction in EG30, whereas Ob- $\mathrm{R}$ was observed in both groups, without difference between them. A possible role of leptin as an inducer of hepatic mitochondrial beta-oxidation has been postulated. Huang et al. demonstrated that leptin in vivo enhances the activity of the fatty acid oxidative pathway in the liver, thus contributing to the reduction of triglycerides and VLDL-cholesterol in rats without leptin resistance [58]. On the other hand, some authors observed increased mitochondrial beta-oxidation in the liver of leptin deficient mice (ob/ob) with severe steatosis [59]. Cao et al. showed that leptin, in the long term, can cause hepatic fibrosis due to the increase of the local levels of oxidative stress [60]. Therefore, it is possible to hypothesize that leptin may play a protective role in the early stages of NAFLD; and, at later stages, it may contribute to the development of fibrosis. Further studies are necessary to clarify the biological function of leptin in the normal liver and its possible role in dietinduced NAFLD.

Hepatic steatosis and hepatocellular ballooning-early stages of NAFLD - were present in all liver samples of the EG 
from week 10. At the final stage of the investigation, although more exuberant steatosis was expected, the pattern was similar to that observed at week 10 . The duration of the study may not have been long enough to allow the development of more severe steatosis and the histological changes that characterize NASH. As the hepatic lesions that occur in $\mathrm{NASH}$ are associated with the expression of proinflammatory cytokines in the liver, it is possible that their investigation could have demonstrated NASH at an early stage. In addition, genetic factors could be acting. It is also possible to speculate that the high levels of leptin could be exerting a protective effect.

MDA, a marker of lipid peroxidation, presented exuberant expression in the EG, whereas this reaction was negative in the CG. Oxidative stress induced by lipid peroxidation is a result of oxidant/antioxidant system imbalance [61]. Cellular stimulation by ROS and the subsequent inflammatory response have been described as the "second hit" that culminate with the development of NASH $[62,63]$. In this context, we found in EG30 a reduction in the levels of the antioxidants enzymes SOD and CAT. This observation suggests that during the initial phases of the experiment there was a balance between antioxidants/prooxidants constituents; however, over time, an imbalance in favor of prooxidants was developed. The use of diets with high amounts of simple carbohydrates induces hypertriglyceridemia resulting in reduction of the antioxidants reserves $[64,65]$.

Although we observed hepatocellular ballooning denoting cell injury, one limitation of our study is the fact of not detecting NASH histologically. This was also a finding in several of the previous models in which NAFLD was induced by a simple carbohydrate-rich diet [28, 36-44]. As stated above, it is possible that the time of the experiment was not long enough to enable the development of the histological characteristics of NASH, which may require higher levels of ROS and/or longer exposure to the offending agent, in addition to liver susceptibility probably related to genetically determined factors, such as preexisting defects in mitochondrial oxidative phosphorylation $[66,67]$. In the presence of intense and sustained production, ROS can cause damage to cell membranes, proteins, and DNA, leading to the release of proinflammatory cytokines, activation of hepatic stellate cells, fibrogenesis, and direct liver damage [68].

Exercise is considered an effective resource for controlling metabolic changes associated with obesity [69]. The physical training used in this study was effective in increasing HDLcholesterol, corroborating the findings from a study in Zucker rats [70]. On the other hand, other authors found no significant effect on HDL-cholesterol in rats or mice submitted to physical training $[71,72]$. No other metabolic parameter suffered alteration in response to physical exercise, which could have been due, at least partially, to the time not long enough of the physical training. In this context, 12 weeks of regular exercise reduced liver triglyceride content and serum levels of LDL-cholesterol in the KK/Ta mice fed a highsucrose diet [72]. In humans, evidence suggests that regular exercise reduces the risk factors for NASH $[1,8]$.

\section{Conclusion}

Our study demonstrated that a diet enriched with sucrose induced obesity, insulin resistance, diabetes, oxidative stress, and subsequent hepatic steatosis and hepatocellular ballooning. The lack of histologically evident inflammation and fibrosis in the liver parenchyma may have been due to the insufficient time of the experiment.

\section{Conflict of Interests}

The authors declare that there is no conflict of interests regarding the publication of this paper.

\section{Acknowledgment}

The study was supported by the Fundação de Amparo à Pesquisa do Estado de Minas Gerais (FAPEMIG) grant (CDS463/2006).

\section{References}

[1] K. Hassan, V. Bhalla, M. E. El Regal, and H. Hesham A-Kader, "Nonalcoholic fatty liver disease: a comprehensive review of a growing epidemic," World Journal of Gastroenterology, vol. 20, no. 34, pp. 12082-12101, 2014.

[2] S. S. Elliott, N. L. Keim, J. S. Stern, K. Teff, and P. J. Havel, "Fructose, weight gain, and the insulin resistance syndrome," The American Journal of Clinical Nutrition, vol. 76, no. 5, pp. 911-922, 2002.

[3] V. S. Malik and F. B. Hu, "Sweeteners and risk of obesity and type 2 Diabetes: the role of sugar-sweetened beverages," Current Diabetes Reports, vol. 12, no. 2, pp. 195-203, 2012.

[4] E. Ravussin, "Physiology: a NEAT way to control weight?" Science, vol. 307, no. 5709, pp. 530-531, 2005.

[5] C. D. Byrne and G. Targher, "NAFLD: a multisystem disease," Journal of Hepatology, vol. 62, no. 1, pp. S47-S64, 2015.

[6] J. P. Ong and Z. M. Younossi, "Epidemiology and natural history of NAFLD and NASH," Clinics in Liver Disease, vol. 11, no. 1, pp. $1-16,2007$.

[7] B. Q. Starley, C. J. Calcagno, and S. A. Harrison, "Nonalcoholic fatty liver disease and hepatocellular carcinoma: a weighty connection," Hepatology, vol. 51, no. 5, pp. 1820-1832, 2010.

[8] S. M. El-Kader and E. M. El-Den Ashmawy, "Non-alcoholic fatty liver disease: the diagnosis and management," World Journal of Hepatology, vol. 7, no. 6, pp. 846-858, 2015.

[9] G. Marchesini, M. Brizi, A. M. Morselli-Labate et al., "Association of nonalcoholic fatty liver disease with insulin resistance," The American Journal of Medicine, vol. 107, no. 5, pp. 450-455, 1999.

[10] A. J. Sanyal, C. Campbell-Sargent, F. Mirshahi et al., "Nonalcoholic steatohepatitis: association of insulin resistance and mitochondrial abnormalities," Gastroenterology, vol. 120, no. 5, pp. 1183-1192, 2001.

[11] E. Albano, E. Mottaran, M. Vidali et al., "Immune response towards lipid peroxidation products as a predictor of progression of non-alcoholic fatty liver disease to advanced fibrosis," Gut, vol. 54, no. 7, pp. 987-993, 2005.

[12] Q. M. Anstee and R. D. Goldin, "Mouse models in non-alcoholic fatty liver disease and steatohepatitis research," International Journal of Experimental Pathology, vol. 87, no. 1, pp. 1-16, 2006. 
[13] F. Marra, A. Gastaldelli, G. Svegliati Baroni, G. Tell, and C. Tiribelli, "Molecular basis and mechanisms of progression of non-alcoholic steatohepatitis," Trends in Molecular Medicine, vol. 14, no. 2, pp. 72-81, 2008.

[14] Y. Takahashi, Y. Soejima, and T. Fukusato, "Animal models of nonalcoholic fatty liver disease/ nonalcoholic steatohepatitis," World Journal of Gastroenterology, vol. 18, no. 19, pp. 2300-2308, 2012.

[15] J. A. Harrold, P. S. Widdowson, J. C. Clapham, and G. Williams, "Individual severity of dietary obesity in unselected Wistar rats: relationship with hyperphagia," The American Journal of Physiology-Endocrinology and Metabolism, vol. 279, no. 2, pp. E340-E347, 2000.

[16] E. L. B. Novelli, Y. S. Diniz, C. M. Galhardi et al., "Anthropometrical parameters and markers of obesity in rats," Laboratory Animals, vol. 41, no. 1, pp. 111-119, 2007.

[17] F. Priviero, G. De Nucci, E. Antunes, and A. Zanesco, "Negative chronotropic response to adenosine receptor stimulation in rat right atria after run training," Clinical and Experimental Pharmacology \& Physiology, vol. 31, no. 10, pp. 741-743, 2004.

[18] S. Dieterich, U. Bieligk, K. Beulich, G. Hasenfuss, and J. Prestle, "Gene expression of antioxidative enzymes in the human heart: increased expression of catalase in the end-stage failing heart," Circulation, vol. 101, no. 1, pp. 33-39, 2000.

[19] D. P. Nelson and L. A. Kiesow, "Enthalpy of decomposition of hydrogen peroxide by catalase at $25^{\circ} \mathrm{C}$ (with molar extinction coefficients of $\mathrm{H}_{2} \mathrm{O}_{2}$ solutions in the UV)," Analytical Biochemistry, vol. 49, no. 2, pp. 474-478, 1972.

[20] E. M. Brunt, C. G. Janney, A. M. Di Bisceglie, B. A. Neuschwander-Tetri, and B. R. Bacon, "Nonalcoholic steatohepatitis: a proposal for grading and staging the histological lesions," The American Journal of Gastroenterology, vol. 94, no. 9, pp. 2467-2474, 1999.

[21] C. S. Lieber, M. A. Leo, K. M. Mak et al., "Model of nonalcoholic steatohepatitis," The American Journal of Clinical Nutrition, vol. 79, no. 3, pp. 502-509, 2004.

[22] B. Wahlang, K. C. Falkner, B. Gregory et al., "Polychlorinated biphenyl 153 is a diet-dependent obesogen that worsens nonalcoholic fatty liver disease in male C57BL6/J mice," The Journal of Nutritional Biochemistry, vol. 24, no. 9, pp. 1587-1595, 2013.

[23] A. Nakamura and Y. Terauchi, "Lessons from mouse models of high-fat diet-induced NAFLD," International Journal of Molecular Sciences, vol. 14, no. 11, pp. 21240-21257, 2013.

[24] S. J. Lee, J. H. Kang, S. Y. Choi, K. T. Suk, D. J. Kim, and O.-S. Kwon, "PKC $\delta$ as a regulator for TGF $\beta 1$-induced $\alpha$-SMA production in a murine nonalcoholic steatohepatitis model," PLoS ONE, vol. 8, no. 2, Article ID e55979, 2013.

[25] H. Okubo, H. Sakoda, A. Kushiyama et al., "Lactobacillus casei strain shirota protects against nonalcoholic steatohepatitis development in a rodent model," American Journal of Physiology-Gastrointestinal and Liver Physiology, vol. 305, no. 12, pp. G911-G918, 2013.

[26] M. K. Pickens, H. Ogata, R. K. Soon, J. P. Grenert, and J. J. Maher, "Dietary fructose exacerbates hepatocellular injury when incorporated into a methionine-choline-deficient diet," Liver International, vol. 30, no. 8, pp. 1229-1239, 2010.

[27] T. Ishimoto, M. A. Lanaspa, C. J. Rivard et al., "High-fat and high-sucrose (western) diet induces steatohepatitis that is dependent on fructokinase," Hepatology, vol. 58, no. 5, pp. 16321643, 2013.

[28] R. Kohli, M. Kirby, S. A. Xanthakos et al., "High-fructose, medium chain trans fat diet induces liver fibrosis and elevates plasma coenzyme Q9 in a novel murine model of obesity and nonalcoholic steatohepatitis," Hepatology, vol. 52, no. 3, pp. 934944, 2010.

[29] C. Dorn, J. C. Engelmann, M. Saugspier et al., "Increased expression of c-Jun in nonalcoholic fatty liver disease," Laboratory Investigation, vol. 94, no. 4, pp. 394-408, 2014.

[30] J. P. Son, M.-K. Son, S.-W. Jun et al., "Effects of a new sustainedrelease microsphere formulation of exenatide, DA-3091, on obese and non-alcoholic fatty liver disease mice," Pharmazie, vol. 68, no. 1, pp. 58-62, 2013.

[31] B.-H. Liu, Y.-Y. Lin, Y.-C. Wang et al., "Porcine adiponectin receptor 1 transgene resists high-fat/sucrose diet-induced weight gain, hepatosteatosis and insulin resistance in mice," Experimental Animals, vol. 62, no. 4, pp. 347-360, 2013.

[32] S. K. Panchal, H. Poudyal, J. Waanders, and L. Brown, "Coffee extract attenuates changes in cardiovascular and hepatic structure and function without decreasing obesity in highcarbohydrate, high-fat diet-fed male rats," The Journal of Nutrition, vol. 142, no. 4, pp. 690-697, 2012.

[33] Z. Qi, J. Xue, Y. Zhang, H. Wang, and M. Xie, "Osthole ameliorates insulin resistance by increment of adiponectin release in high-fat and high-sucrose-induced fatty liver rats," Planta Medica, vol. 77, no. 3, pp. 231-235, 2011.

[34] M. Aoun, F. Michel, G. Fouret et al., "A polyphenol extract modifies quantity but not quality of liver fatty acid content in high-fat-high-sucrose diet-fed rats: possible implication of the sirtuin pathway," British Journal of Nutrition, vol. 104, no. 12, pp. 1760-1770, 2010.

[35] J.-H. Fu, H.-S. Sun, Y. Wang, W.-Q. Zheng, Z.-Y. Shi, and Q.-J. Wang, "The effects of a fat- and sugar-enriched diet and chronic stress on nonalcoholic fatty liver disease in male wistar rats," Digestive Diseases and Sciences, vol. 55, no. 8, pp. 2227-2236, 2010.

[36] F. Armutcu, Ö. Coskun, A. Gürel et al., “Thymosin alpha 1 attenuates lipid peroxidation and improves fructose-induced steatohepatitis in rats," Clinical Biochemistry, vol. 38, no. 6, pp. 540-547, 2005.

[37] A. Spruss, G. Kanuri, S. Wagnerberger, S. Haub, S. C. Bischoff, and I. Bergheim, "Toll-like receptor-4 is involved in the development of fructose-induced hepatic steatosis in mice," Hepatology, vol. 50, no. 4, pp. 1094-1104, 2009.

[38] T. Kawasaki, K. Igarashi, T. Koeda et al., "Rats fed fructoseenriched diets have characteristics of nonalcoholic hepatic steatosis," Journal of Nutrition, vol. 139, no. 11, pp. 2067-2071, 2009.

[39] L. G. Sánchez-Lozada, W. Mu, C. Roncal et al., "Comparison of free fructose and glucose to sucrose in the ability to cause fatty liver," European Journal of Nutrition, vol. 49, no. 1, pp. 1-9, 2010.

[40] K. Nomura and T. Yamanouchi, "The role of fructose-enriched diets in mechanisms of nonalcoholic fatty liver disease," The Journal of Nutritional Biochemistry, vol. 23, no. 3, pp. 203-208, 2012.

[41] K. Nojima, K. Sugimoto, H. Ueda, N. Babaya, H. Ikegami, and H. Rakugi, "Analysis of hepatic gene expression profile in a spontaneous mouse model of type 2 diabetes under a high sucrose diet," Endocrine Journal, vol. 60, no. 3, pp. 261-274, 2013.

[42] Y.-S. Song, C.-H. Fang, B.-I. So, J.-Y. Park, D. W. Jun, and K.S. Kim, "Therapeutic effects of granulocyte-colony stimulating factor on non-alcoholic hepatic steatosis in the rat," Annals of Hepatology, vol. 12, no. 1, pp. 115-122, 2013.

[43] C. A. Roncal-Jimenez, M. A. Lanaspa, C. J. Rivard et al., "Sucrose induces fatty liver and pancreatic inflammation 
in male breeder rats independent of excess energy intake," Metabolism: Clinical and Experimental, vol. 60, no. 9, pp. 12591270, 2011.

[44] V. Volynets, A. Spruss, G. Kanuri, S. Wagnerberger, S. C. Bischoff, and I. Bergheim, "Protective effect of bile acids on the onset of fructose-induced hepatic steatosis in mice," The Journal of Lipid Research, vol. 51, no. 12, pp. 3414-3424, 2010.

[45] E. Ip, G. C. Farrell, G. Robertson, P. Hall, R. Kirsch, and I. Leclercq, "Central role of PPAR $\alpha$-dependent hepatic lipid turnover in dietary steatohepatitis in mice," Hepatology, vol. 38, no. 1, pp. 123-132, 2003.

[46] M. Carmiel-Haggai, A. I. Cederbaum, and N. Nieto, "A high-fat diet leads to the progression of non-alcoholic fatty liver disease in obese rats," The FASEB Journal, vol. 19, no. 1, pp. 136-138, 2005.

[47] K. Wouters, P. J. van Gorp, V. Bieghs et al., "Dietary cholesterol, rather than liver steatosis, leads to hepatic inflammation in hyperlipidemic mouse models of nonalcoholic steatohepatitis," Hepatology, vol. 48, no. 2, pp. 474-486, 2008.

[48] B. A. Neuschwander-Tetri, "Carbohydrate intake and nonalcoholic fatty liver disease," Current Opinion in Clinical Nutrition and Metabolic Care, vol. 16, no. 4, pp. 446-452, 2013.

[49] P. Paschos and K. Paletas, "Non alcoholic fatty liver disease and metabolic syndrome," Hippokratia, vol. 13, no. 1, pp. 9-19, 2009.

[50] J. D. Sparks, C. E. Sparks, and K. Adeli, "Selective hepatic insulin resistance, VLDL overproduction, and hypertriglyceridemia," Arteriosclerosis, Thrombosis, and Vascular Biology, vol. 32, no. 9, pp. 2104-2112, 2012.

[51] J.-M. Schwarz, P. Linfoot, D. Dare, and K. Aghajanian, "Hepatic de novo lipogenesis in normoinsulinemic and hyperinsulinemic subjects consuming high-fat, low-carbohydrate and lowfat, high-carbohydrate isoenergetic diets," The American Journal of Clinical Nutrition, vol. 77, no. 1, pp. 43-50, 2003.

[52] A. Aarsland, D. Chinkes, and R. R. Wolfe, "Contributions of de novo synthesis of fatty acids to total VLDL-triglyceride secretion during prolonged hyperglycemia/hyperinsulinemia in normal man," The Journal of Clinical Investigation, vol. 98, no. 9, pp. 2008-2017, 1996.

[53] L. C. Hudgins, M. K. Hellerstein, C. E. Seidman, R. A. Neese, J. D. Tremaroli, and J. Hirsch, "Relationship between carbohydrate-induced hypertriglyceridemia and fatty acid synthesis in lean and obese subjects," The Journal of Lipid Research, vol. 41, no. 4, pp. 595-604, 2000.

[54] J. M. Friedman and J. L. Halaas, "Leptin and the regulation of body weight in mammals," Nature, vol. 395, no. 6704, pp. 763770, 1998

[55] L. Vilà, N. Roglans, M. Alegret, R. M. Sánchez, M. VázquezCarrera, and J. C. Laguna, "Suppressor of cytokine signaling-3 (SOCS-3) and a deficit of serine/threonine (Ser/Thr) phosphoproteins involved in leptin transduction mediate the effect of Fructose on rat liver lipid metabolism," Hepatology, vol. 48, no. 5, pp. 1506-1516, 2008.

[56] S. Chitturi, G. Farrell, L. Frost et al., "Serum leptin in NASH correlates with hepatic steatosis but not fibrosis: a manifestation of lipotoxicity?" Hepatology, vol. 36, no. 2, pp. 403-409, 2002.

[57] C. S. Mantzoros, "The role of leptin and hypothalamic neuropeptides in energy homeostasis: update on leptin in obesity," Growth Hormone and IGF Research, vol. 11, supplement A, pp. S85-S89, 2001.

[58] W. Huang, N. Dedousis, A. Bandi, G. D. Lopaschuk, and R. M. O’Doherty, "Liver triglyceride secretion and lipid oxidative metabolism are rapidly altered by leptin in vivo," Endocrinology, vol. 147, no. 3, pp. 1480-1487, 2006.

[59] L. J. Brady, P. S. Brady, D. R. Romsos, and C. L. Hoppel, "Elevated hepatic mitochondrial and peroxisomal oxidative capacities in fed and starved adult obese (ob/ob) mice," Biochemical Journal, vol. 231, no. 2, pp. 439-444, 1985.

[60] Q. Cao, K. M. Mak, C. Ren, and C. S. Lieber, "Leptin stimulates tissue inhibitor of metalloproteinase-1 in human hepatic stellate cells: respective roles of the JAK/STAT and JAK-mediated $\mathrm{H}_{2} \mathrm{O}_{2}$-dependent MAPK pathways," Journal of Biological Chemistry, vol. 279, no. 6, pp. 4292-4304, 2004.

[61] H. Sies and W. Stahl, "Vitamins E and C, beta-carotene, and other carotenoids as antioxidants," The American Journal of Clinical Nutrition, vol. 62, no. 6, supplement, pp. 1315S-1321S, 1995.

[62] O. F. W. James and C. P. Day, "Non-alcoholic steatohepatitis (NASH): a disease of emerging identity and importance," Journal of Hepatology, vol. 29, no. 3, pp. 495-501, 1998.

[63] S. Seki, T. Kitada, T. Yamada, H. Sakaguchi, K. Nakatani, and K. Wakasa, "In situ detection of lipid peroxidation and oxidative DNA damage in non-alcoholic fatty liver diseases," Journal of Hepatology, vol. 37, no. 1, pp. 56-62, 2002.

[64] J. Busserolles, E. Gueux, E. Rock, A. Mazur, and Y. Rayssiguier, "Substituting honey for refined carbohydrates protects rats from hypertriglyceridemic and prooxidative effects of fructose," The Journal of Nutrition, vol. 132, no. 11, pp. 3379-3382, 2002.

[65] I. A. Leclercq, "Antioxidant defence mechanisms: new players in the pathogenesis of non-alcoholic steatohepatitis?" Clinical Science, vol. 106, no. 3, pp. 235-237, 2004.

[66] J. L. Martindale and N. J. Holbrook, "Cellular response to oxidative stress: signaling for suicide and survival," Journal of Cellular Physiology, vol. 192, no. 1, pp. 1-15, 2002.

[67] D. Pessayre, A. Mansouri, and B. Fromenty, "Nonalcoholic steatosis and steatohepatitis. V. Mitochondrial dysfunction in steatohepatitis," The American Journal of PhysiologyGastrointestinal and Liver Physiology, vol. 282, no. 2, pp. G193G199, 2002.

[68] G. C. Farrell, D. van Rooyen, L. Gan, and S. Chitturi, "NASH is an inflammatory disorder: pathogenic, prognostic and therapeutic implications," Gut and Liver, vol. 6, no. 2, pp. 149-171, 2012.

[69] C. Y. Christ, D. Hunt, J. Hancock, R. Garcia-Macedo, L. J. Mandarino, and J. L. Ivy, "Exercise training improves muscle insulin resistance but not insulin receptor signaling in obese Zucker rats," Journal of Applied Physiology, vol. 92, no. 2, pp. 736-744, 2002.

[70] J. L. Durstine, K. A. Kenno, and R. E. Shepherd, "Serum lipoproteins of the Zucker rat in response to an endurance running program," Medicine and Science in Sports and Exercise, vol. 17, no. 5, pp. 567-573, 1985.

[71] C. H. D. J. Pinheiro, W. M. D. S. Filho, J. D. O. Neto et al., "Exercise prevents cardiometabolic alterations induced by chronic use of glucocorticoids," Arquivos Brasileiros de Cardiologia, vol. 93, no. 4, pp. 372-408, 2009.

[72] W. Aoi, Y. Naito, L. P. Hang et al., "Regular exercise prevents high-sucrose diet-induced fatty liver via improvement of hepatic lipid metabolism," Biochemical and Biophysical Research Communications, vol. 413, no. 2, pp. 330-335, 2011. 


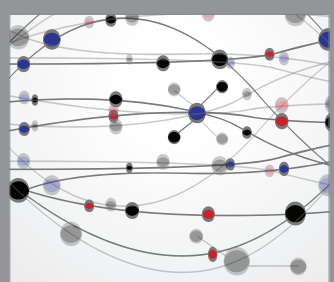

The Scientific World Journal
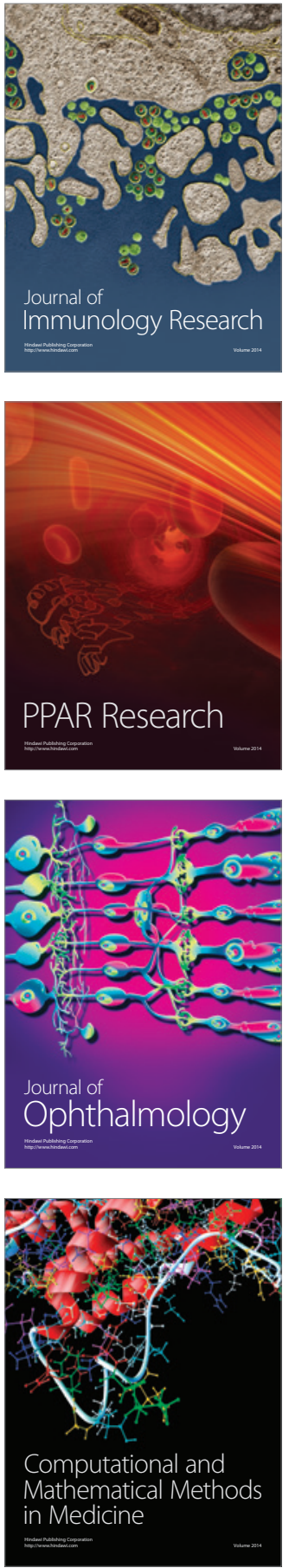

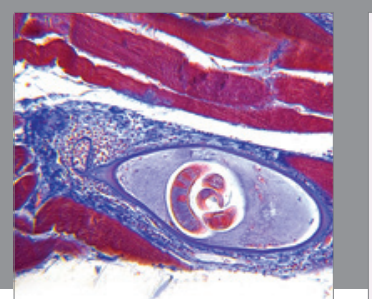

Gastroenterology Research and Practice

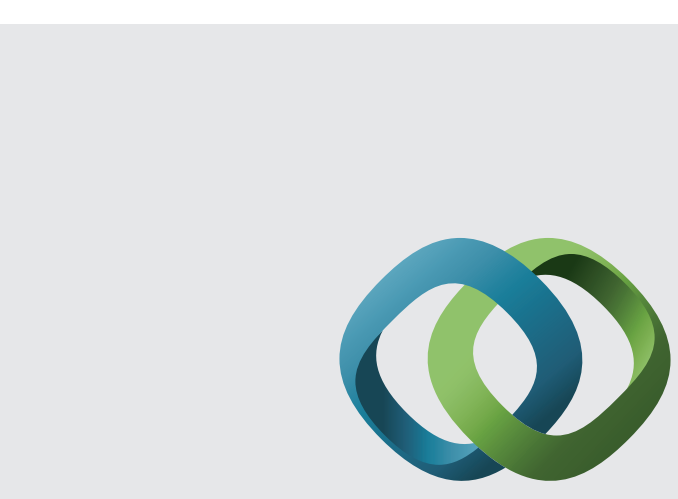

\section{Hindawi}

Submit your manuscripts at

http://www.hindawi.com
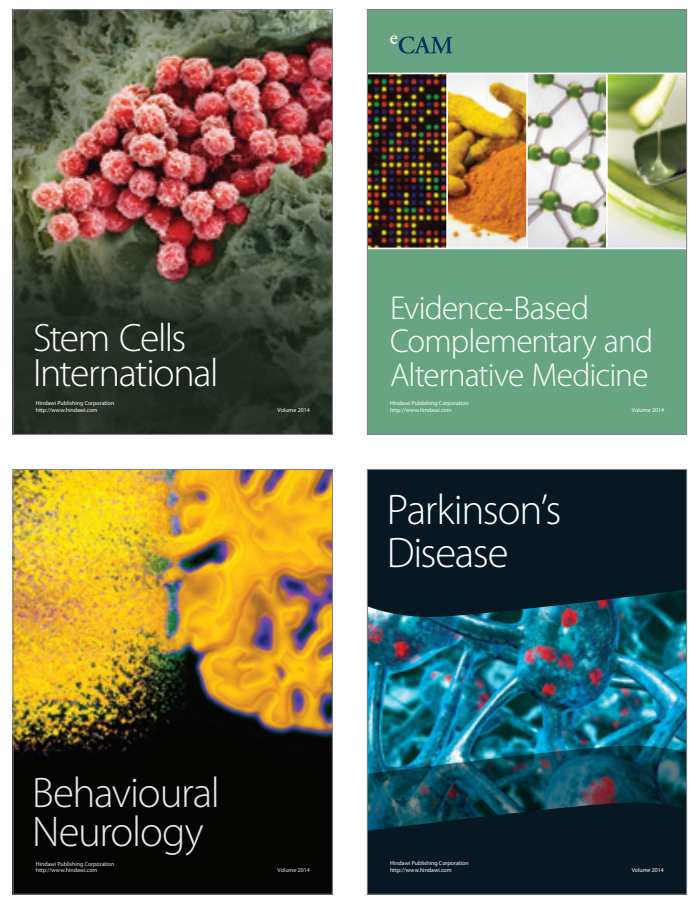
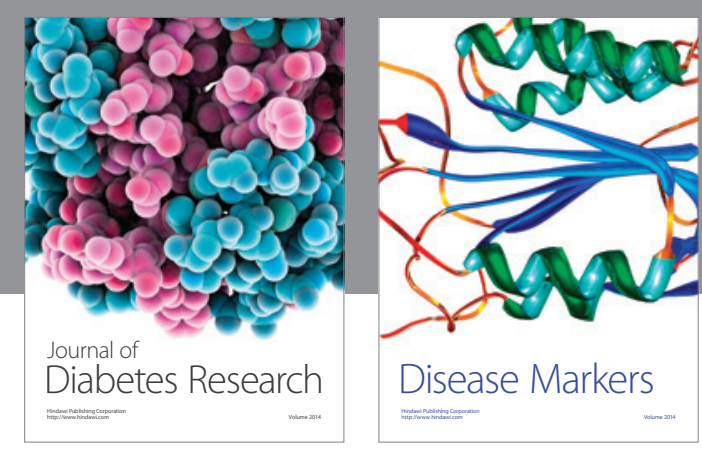

Disease Markers
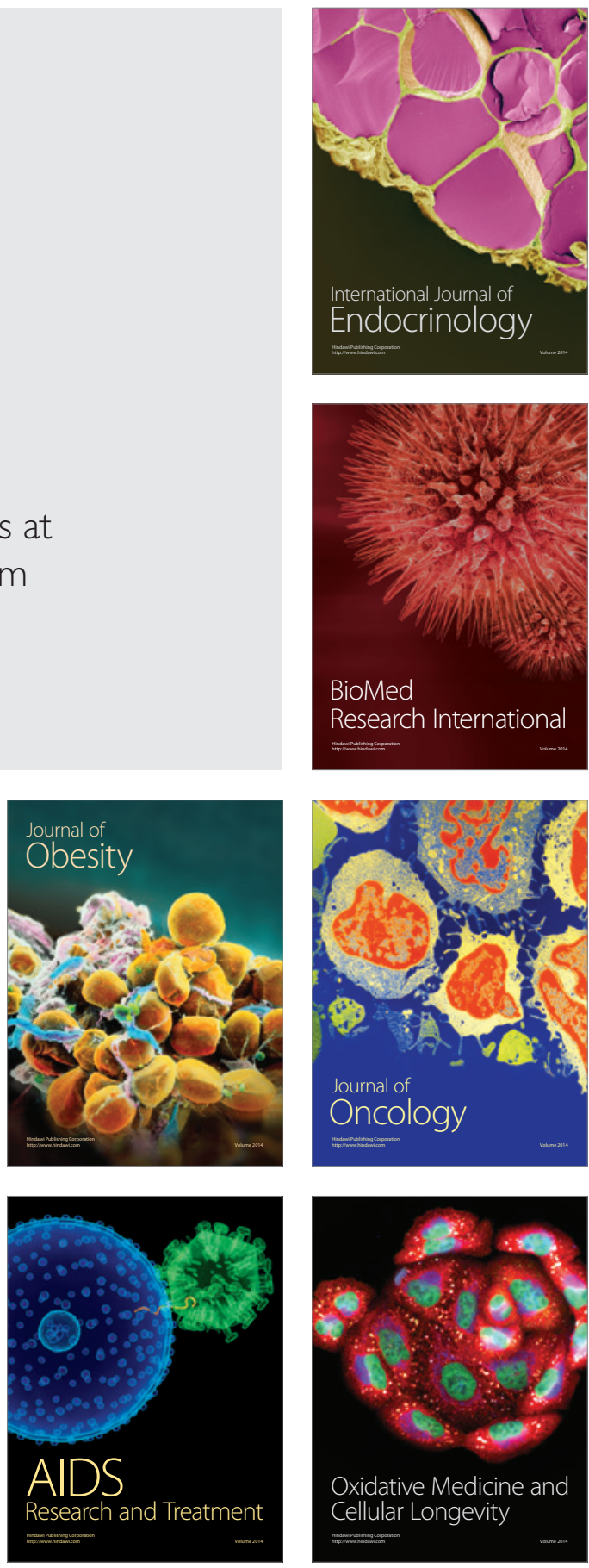